\title{
EVALUATION OF ANTIOXIDANT POTENTIAL OF TAPINANTHUS GLOBIFERUS EXTRACT AND EFFECT ON PHYSIOLOGIC STATE OF DEFENSIVE ANTIOXIDANT ENZYMES IN WISTAR RATS
}

\author{
${ }^{1}$ TUGBOBO, O.S., ${ }^{1}$ IDOWU, K.S., ${ }^{2}$ FAYOSE, T.S., ${ }^{3}$ AYOADE, R.O. \\ ${ }^{1}$ Department of Science Technology, Federal Polytechnic, Ado-Ekiti, Nigeria \\ ${ }^{2}$ Department of Mathematics and Statistics, Federal Polytechnic, Ado-Ekiti, Nigeria \\ ${ }^{3}$ Department of Chemical Sciences, Joseph Ayo Babalola University, Ikeji-Arakeji, Nigeria
}

DOI: $10.31364 / \mathrm{SCIRJ} / \mathrm{v} 7 . \mathrm{i9} .2019 . P 0919702$

http://dx.doi.org/10.31364/SCIRJ/v7.i9.2019.P0919702

\begin{abstract}
The present investigation on this study was to assess the antioxidant and toxicological potentials of Tapinanthus globiferus leaf extract and its effects on inherent antioxidant enzymes. The leaf extracts of the plant were prepared with both aqueous and ethanolic solvents at 5\% concentration levels. Antioxidant indices such as free radical scavenging ability [DPPH], iron chelation ability $\left[\mathrm{Fe}^{2+}\right]$, hydroxyl radical scavenging ability $\left[\mathrm{OH}^{*}\right]$, which are indices for radical scavenging potential of Tapinanthus globiferus were assessed. Toxicological effect of the plant extract was equally investigated on defensive antioxidant enzymes in rat liver. The results indicate that the extracts exhibited antioxidant properties at significant $(\mathrm{P}<0.05)$ levels where the radical scavenging ability of the extracts were ascertained with percentage inhibition in the range $(65-41.1) \% \mathrm{DPPH},(60-77.5) \% \mathrm{Fe}^{2+}$ chelation, $(17.5-34.2) \% \mathrm{OH}^{*}$. Hence, highest percentage inhibition was observed against $\mathrm{Fe}^{2+}$ where the extract demonstrated high level of iron chelating ability at relatively low extract concentration $(1.0 \mathrm{mg} / \mathrm{ml})$. Also the results from toxicological assay indicate synergistic effect of the extract on defensive antioxidant enzymes with concomitant increase in their activities corresponding to increase in extract concentration. The results suggest that Tapinanthus globiferus could serve as reliable antioxidant dietary supplement and perhaps not toxic at the concentrations investigated.
\end{abstract}

Keywords: Tapinanthus globiferus, antioxidant enzymes, free radicals, percentage inhibition.

\section{INTRODUCTION}

Medicinal plants possess strong antioxidant activity and may help to protect the cells against oxidative damage usually caused by free radicals (Hatano et al., 1989). They are well known as radical scavengers, metal chelators, reducing agents as well as antioxidant from plant materials which terminate action of free radicals, thereby protecting the body from various diseases (Roja and Rao, 2000). Tapinanthus globiferus naturally grows and is very common in the tropics especially in the southern part of Nigeria (Houghton, 2002)) and it has been reported that shoot of this plant is partly used in folk medicine to treat myriad of diseases. Besides, free radicals such as superoxide anions, hydroxyl radicals and hydrogen peroxides play crucial role in the development of oxidative stress related ailments such as arthritis, asthma, dementia, cancer and Parkinson's disease. The free radicals in human body are generated through aerobic respiration and as well from exogenous sources (Blois 1988). However, oxidative stress can result when the critical balance between free radical generation and antioxidant defense system is unfavorable (Halliwell and Gutteridge, 1981). This oxidative damage could be salvaged by endogenous defense system such as reduced glutathione [GSH], glutathione peroxidase [GPx], superoxide dismutase [SOD] and catalase [CAT] which are antioxidant enzyme that work in concert to detoxify the free radicals (Das and Nair, 1980). The present study evaluated the antioxidant properties or potentials of Tapinanthus globiferus extract and its effects on the endogenous defensive antioxidant enzymes in wistar rats.

\section{MATERIALS AND METHODS}




\section{Plant collection}

Tapinanthus globiferus leaves were obtained from different local areas at Ibadan, Oyo state, Nigeria. Identification and authentication were carried out at Agricultural Research Institute, Moore Plantation, Apata, Ibadan with herbarium number UHA $2018 / 137$. Thereafter the leaves were air dried for 28 days at room temperature. The air dried leaves were ground to fine powder and used in this study.

\section{Determination of DPPH Radical Scavenging Activity}

The free radical scavenging activity of Tapinanthus globiferus leaf extract was measured by 1,1diphenyl-2-picryl-hydrazyl (DPPH) using method described by (Mensor et al., 2001). $0.1 \mathrm{mM}$ solution of DPPH in ethanol was prepared and $1 \mathrm{~mL}$ of the solution was added to $3 \mathrm{~mL}$ of extract suspension in water at different concentrations, incubated for $30 \mathrm{mins}$ and absorbance measured at $517 \mathrm{~nm}$.

\section{Determination of Iron Chelation $\left(\mathrm{Fe}^{2+}\right)$ Ability}

The $\mathrm{Fe} 2^{+}$chelating ability of the extracts were determined using method described by (Minotti and Aust, 1987). Freshly prepared $500 \mu$ molL-1 FeSO4 $(150 \mu \mathrm{L})$ were added to a reaction mixture containing $168 \mu \mathrm{L}$ of $0.1 \mathrm{molL}-1 \mathrm{Tris}-\mathrm{HCl}(\mathrm{pH} 7.4), 218 \mu \mathrm{L}$ saline and the extract $(0-25 \mu \mathrm{L})$. The reaction mixture was incubated for $10 \mathrm{~min}$ before adding $13 \mu \mathrm{L}$ of $0.25 \% 1$, 10-phenanthroline (w/v). The absorbance was read at 510nm.

\section{Determination of Hydroxyl (OH*) Radical Scavenging Ability}

Hydroxyl radical scavenging ability was measured by observing interaction between deoxyribose and test compounds for hydroxyl radical generated via $\mathrm{Fe}^{3+}$ - Ascobate-EDTA H2O2-system (Fenton reaction) described by (Halliwell and Gutteridge, 1981).

\section{In vitro antioxidant determined}

\section{Reduced Glutathione (GSH)}

$0.2 \mathrm{ml}$ Tapinanthus globiferus leaf extract was added to $1.8 \mathrm{ml}$ of distilled water and $3 \mathrm{ml}$ of sulphosalicylic acid. The mixture was centrifuged at $3000 \mathrm{xg}$ for $4 \mathrm{~min}$ and $0.5 \mathrm{ml}$ of the supernatant was added to $4.5 \mathrm{ml}$ of Ellman's reagent. A blank was prepared with $0.5 \mathrm{ml}$ of dilute precipitating agent and $4 \mathrm{ml}$ of phosphate buffer with $0.5 \mathrm{ml}$ of Ellman's reagent. The absorbance was taken within 30mins of colour development at 412nm against blank and the concentration of GSH was extrapolated from the GSH standard curve using method by (Buttler et al., 1963).

\section{Glutathione Peroxidase (GPx) Assay}

$500 \mu 1$ Tapinanthus globiferus leaf extract was added to reaction mixture containing 500 $\mu 1$ phosphate buffer $\mathrm{pH} 7.4,100 \mu \mathrm{l}$ sodium azide, $200 \mu \mathrm{l} \mathrm{GSH}$, and $100 \mu \mathrm{l}$ hydrogen peroxide, after which $600 \mu \mathrm{l}$ distilled water was added and mixed thoroughly. The whole reaction mixture was incubated at $37^{\circ} \mathrm{C}$ for $3 \mathrm{mins}$ after which $0.5 \mathrm{ml}$ of TCA was added and later centrifuged at $3000 \mathrm{rpm}$ for $5 \mathrm{mins}$. $\mathrm{K}_{2} \mathrm{HPO}_{4}(2 \mathrm{ml})$ and $1 \mathrm{ml}$ of DNTB was added to $1 \mathrm{ml}$ of each of the supernatants and the absorbance was read at $412 \mathrm{~nm}$ against blank. The GPx activity in the sample was determined according to the method described by (Rotruck et al., 1973).

\section{Superoxide-dismutase (SOD) Assay}


$0.2 \mathrm{ml}$ Tapinanthus globiferus leaf extract was added to $2.5 \mathrm{ml}$ of $0.05 \mathrm{M}$ carbonate buffer of $\mathrm{pH} 10.2$ to equilibrate in the spectrophotometer. The reaction was initiated by the addition of $0.3 \mathrm{ml}$ of freshly prepared $0.3 \mathrm{mM}$ adrenaline to the mixture which was quickly mixed by inversion. The reference cuvette contained $2.5 \mathrm{ml}$ buffer, $0.3 \mathrm{ml}$ of adrenaline and $0.2 \mathrm{ml}$ distilled water. The increase in absorbance at 480nm was monitored every 30 seconds for 150 seconds according to the method described by (Misra and Fridovich, 1972).

\section{Catalase (CAT) Assay}

$70 \mu \mathrm{l}$ Tapinanthus globiferus leaf extract was mixed with $920 \mu \mathrm{l}$ sodium phosphate buffer containing $0.1 \mathrm{mM}$ EDTA at pH 7.0. The reaction was started by adding $10 \mu \mathrm{l}$ of hydrogen peroxide. The decrease in hydrogen peroxide concentration was taken by reading the absorbance at 240nm at 10seconds intervals for 180seconds (Aebi, 1974) method was used to determine the catalase activity:

\section{Data analysis}

Results were expressed as mean value \pm standard error of mean (SEM). Data analysis was done using one-way analysis of variance (ANOVA) followed by Tukey-test. The results were significantly difference at $\mathrm{p}<0.05$.

\section{RESULTS}

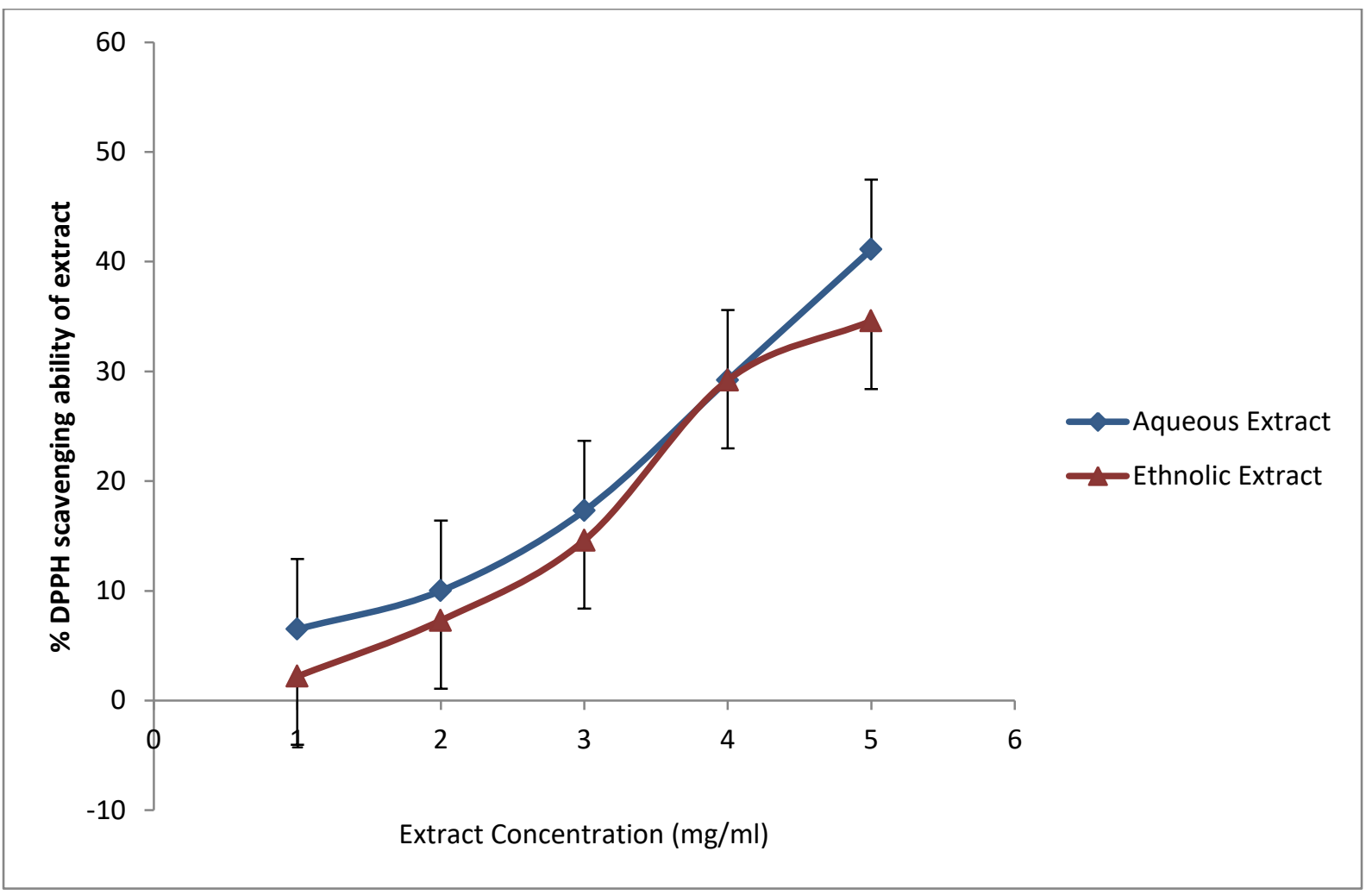

Figure 1: DPPH scavenging ability of Tapinanthus globiferus leaf extract 


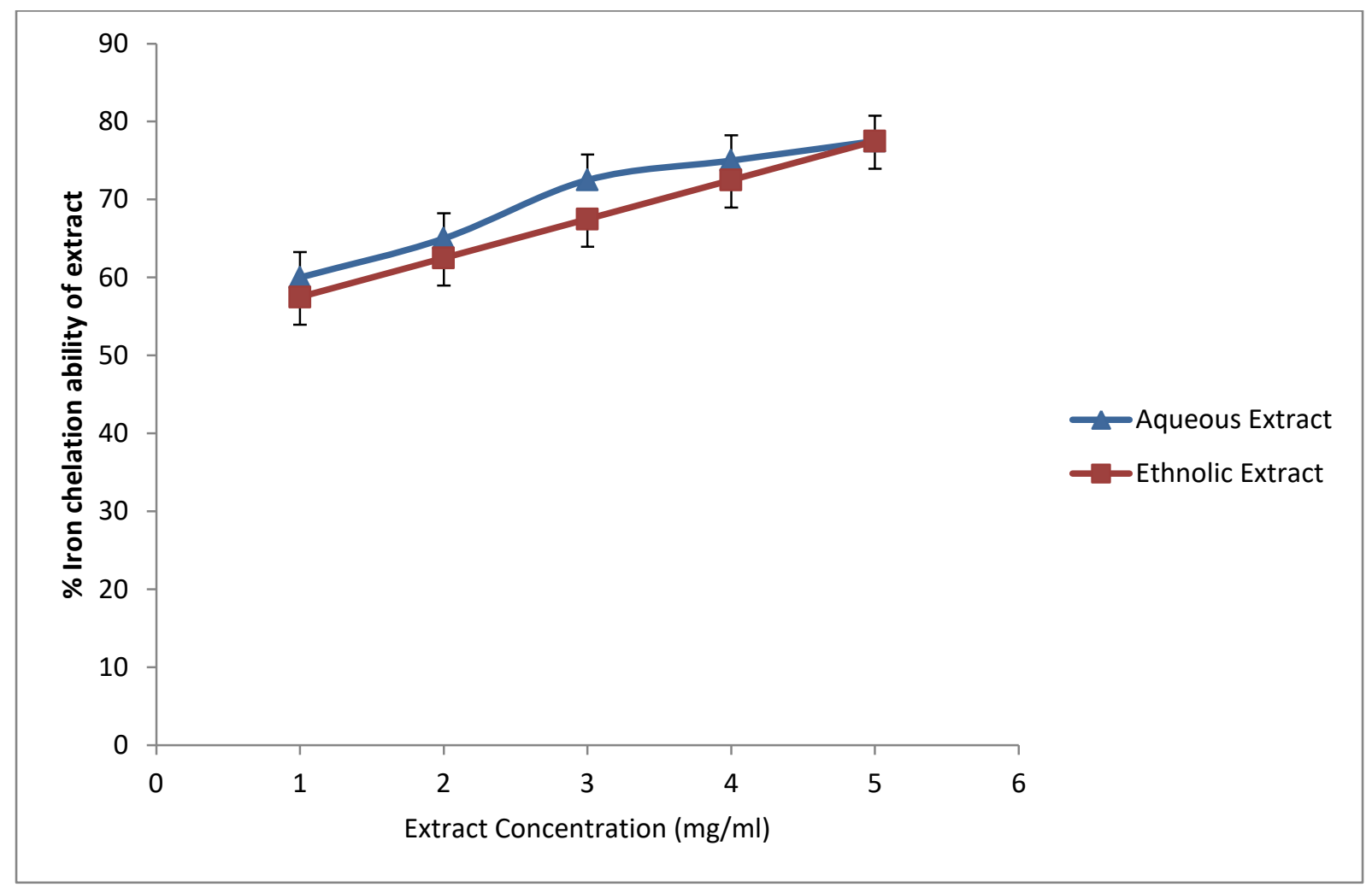

Figure 2: $\mathrm{Fe}^{2+}$ chelating effect of Tapinanthus globiferus leaf extract 


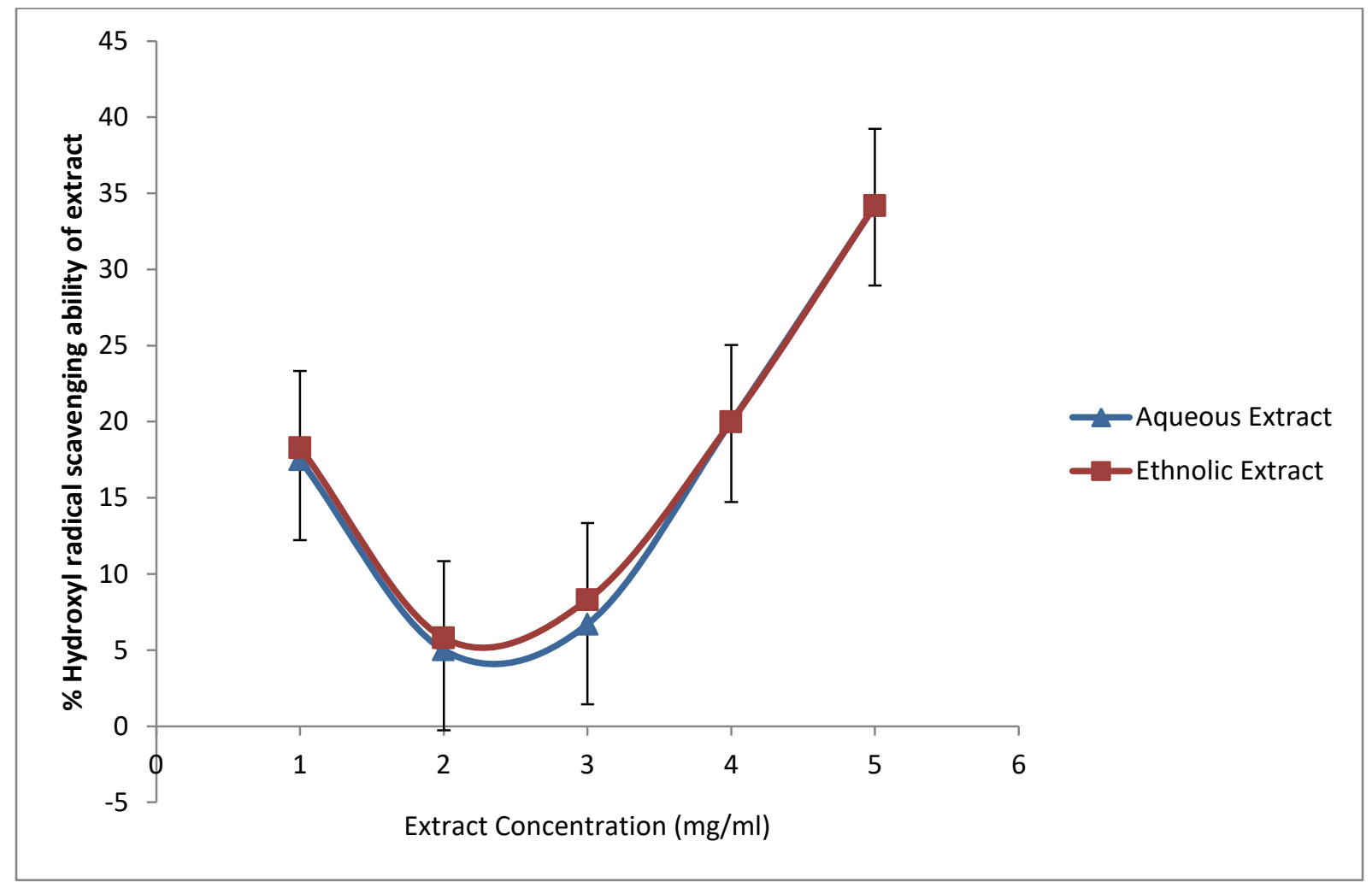

Figure 3: Hydroxyl radical scavenging ability of Tapinanthus globiferus leaf extract

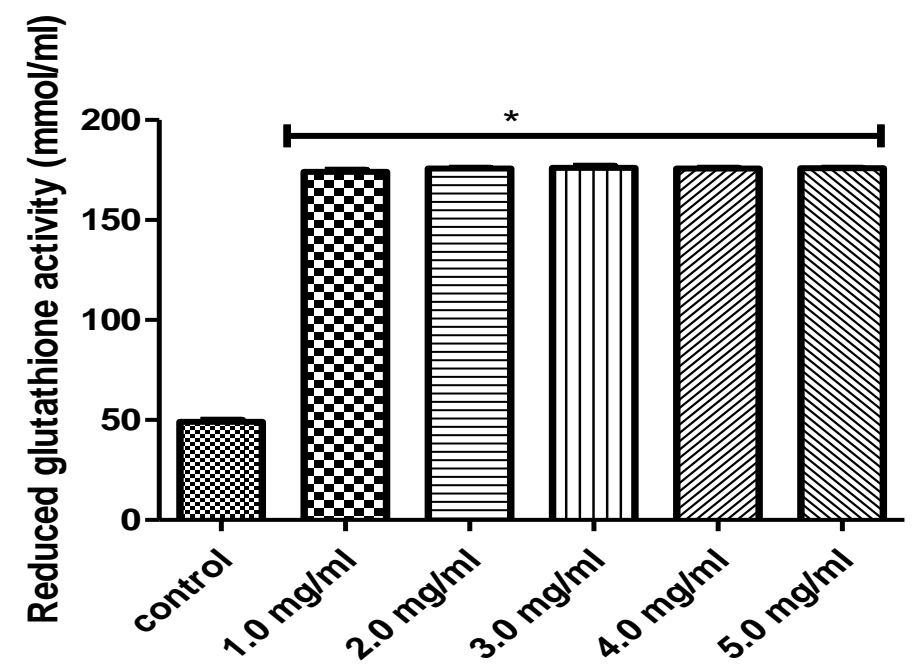

Figure 4: Effect of Tapinanthus globiferus leaf extract on GSH

(Each value is a mean of three determination \pm SEM. * represents statistical difference from control at $p<0.05$ ) 


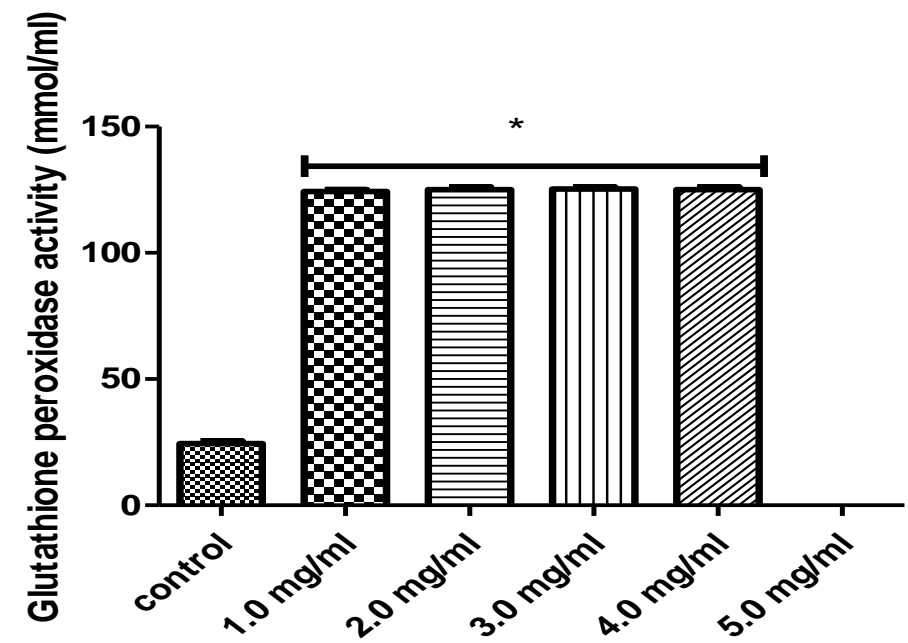

Figure 5: Effect of Tapinanthus globiferus leaf extract on GPx

(Each value is a mean of three determination \pm SEM. * represents statistical difference from control at $\mathrm{p}<0.05)$

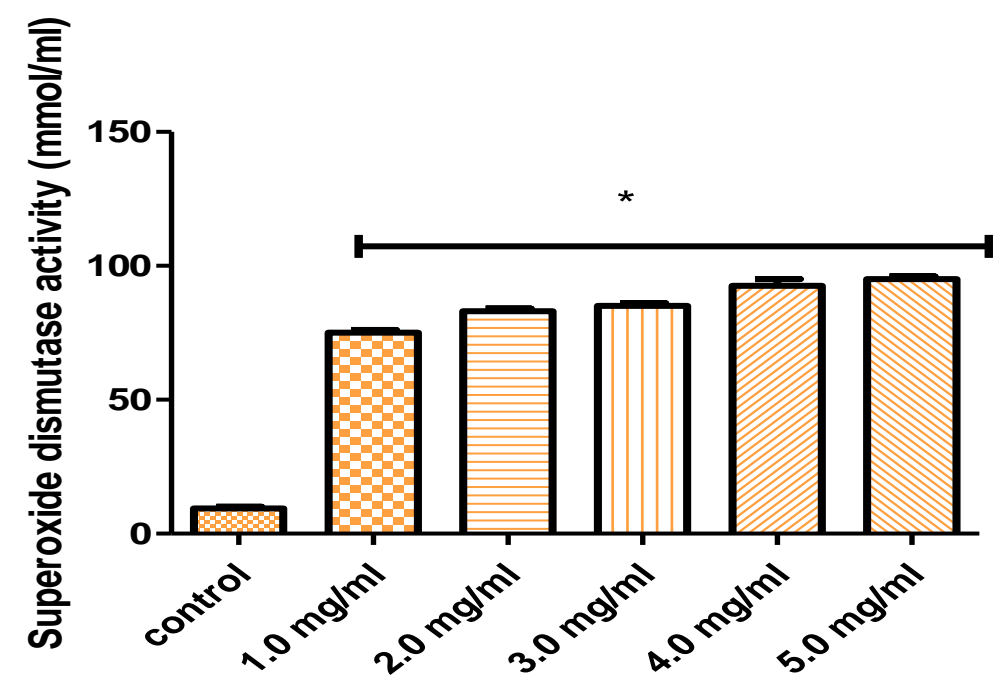

Figure 6: Effect of Tapinanthus globiferus leaf extract on SOD activity

(Each value is a mean of three determination \pm SEM. * represents statistical difference from control at $\mathrm{p}<0.05)$ 


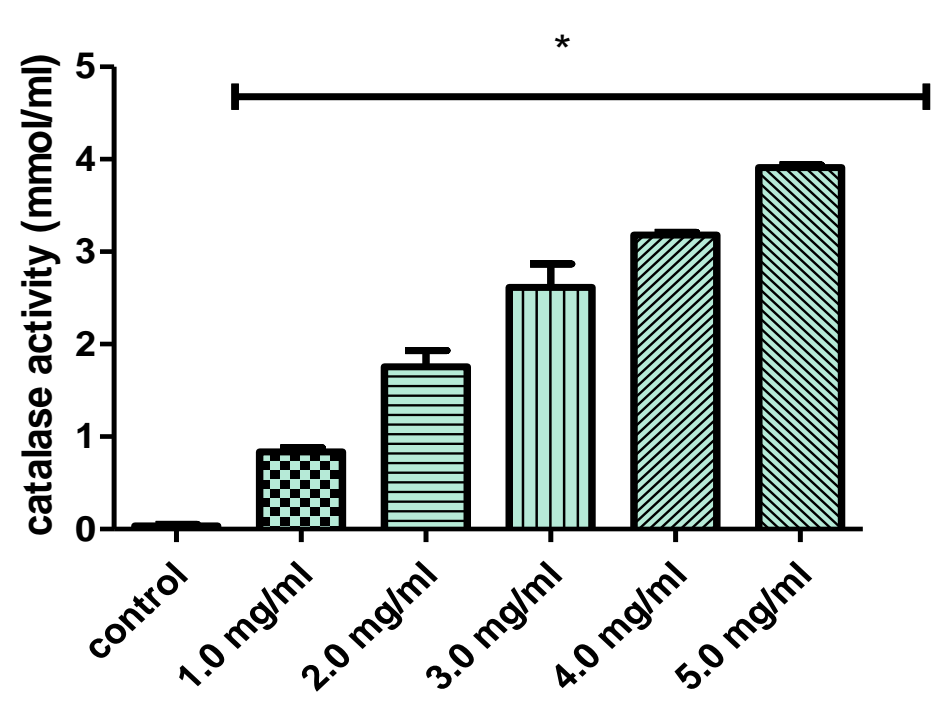

Figure 7: Effect of Tapinanthus globiferus leaf extract on CAT activity

(Each value is a mean of three determination \pm SEM. * represents statistical difference from control at $\mathrm{p}<0.05$ )

\section{DISCUSSION}

The aqueous extract of Tapinanthus globiferus leaf exhibited higher percentage of DPPH scavenging ability than the ethanolic extract (Figure 1). The strong inhibition displayed on these radicals could be linked to the extract inherent phenolic compounds which are capable of donating electrons or tranfering hydrogen atom to neutralize free radicals, thus, could be a promising therapeutic agent to treat oxidative stress-induced pathological conditions. A similar trend of inhibition by the extracts was observed against hydroxyl radicals in Figures 3 where the extracts demonstrated same inhibitory strength. This is contrary to findings of (Ojo et al., 2014) who reported that ethanolic extract of Ocimum gratissimum exhibited higher inhibitory potentials against nitric oxide and hydroxyl radicals. Hydroxy radical have been implicated in the oxidative damage of DNA, proteins and lipids (Spencer et al,. 1994). The formation of hydroxyl radicals in biological systems have been attributed to interactions of metal ions such as ferrous with hydrogen peroxide (McCord and Day, 1987). However, the iron chelating effect of aqueous extract was slightly higher than ethanolic extract (Figure 2). Their inhibitory potentials increased with increased concentration of the extracts. Iron can stimulate lipid peroxidation by Fenton reaction and also accelerates peroxidation by decomposing lipid hydroperoxides into peroxyl or alkoxyl radicals which can abstract hydrogen and perpetuate the chain reaction of lipid peroxidation (Halliwell, 1997). The chelating potential of both extracts in this study suggests that the extracts might afford the cell protection against oxidative stress. This study further buttresses the findings by (Oboh et al., 2007) that chelating agents inhibit radical-mediated oxidative chain reactions in food systems and consequently improve food quality, stability and safety. 
In addition, the results indicate synergistic effect of the extract on the defensive antioxidant enzymes (GSH, GPx, SOD and CAT) with concomitant increase in their activities corresponding to increase in extract concentration as shown in Figure 1, 2, 3, and 4. This effect could be attributed to the presence of flavonoids, selenium and zinc in the extract which generally activate the antioxidant enzymes and prevent rise in concentration of free radicals that cause cellular assault. This may probably be one of the main mechanism of action of this extract in ameliorating renal damage and other oxidative stress diseases.

\section{Acknowledgements}

The authors wish to express their gratitude to Agricultural Research Institute, Moore Plantation, Apata, Ibadan for their assistance during this study.

\section{Conflict of interest}

The authors declare no conflict of interest.

\section{REFERENCES}

Aebi, I.C., (1974). Determination of catalase activity. Plant Physiol. 33: 1071-1074.

Blois, M.S. (1988). Antioxidant determination by the use of stable free radicals. Nature 29: 1199-1201

Butler, J., Gyamfi, M.A., Yonamine, M., Aaniya, Y., (1963). Estimation of glutathione in the liver and brain supernatants. General Pharmacology. 32: 661-667.

Das, S.K. and Nair, R.C. (1980). Superoxide dismutase, glutathione peroxidase, catalase and lipid peroxidation of normal and sickle erythrocytes. Br. J. haematol. 44: 87 - 92.

Mensor, L.L., Meneze, F.S., and Leitao, D.L. (2001). Screening of medicinal plants for antioxidant activities using DPPH free radical method. Phytother. Res. 15: 127-130.

Halliwell, B. (1997). Free radicals, antioxidants and diseases; curiousity, causes and consequence JAMA 281: $157-161$.

Halliwell, B. and Gutteridge, K. (1981). Determination of antioxidant potential on hydroxyl radicals. JAMA 103: 231 -236.

Houghton, P. (2002). The medicinal tree Kigelia pinnata. Journal of Ethnobotany and Scientific Research, 68 (1) : 14-20

Hatano, T., Edamatsu, R., Mori, A., Fujita, Y., Yasuhara, E. (1989). Effects of flavonoids, tannins and related polyphenols on superoxide anion radicals and 1,1, diphenyl-2-picryl-hydrazyl. Chem. Pharm. Bull, 37: 2016-2023.

McCord, J.M. and Day, E.D. (1987). The deoxyribose assay; assay for both hydroxyl radical and site for specific hydroxyl radical production. FEBS Letters, 86: $139-142$.

Roja, G. and Rao, P.S. (2000). Anticancer compounds from tissue cultures of medicinal plants; global importance of medicinal plant resources. J. Herbs. Med. Plants. 7: 71-102.

Misra, H.P. and Fridovich, I. (1972). The role of superoxide anion in the auto-oxidation of epinephrine and simple assay for superoxide dismutase. J. Biol. Chem. 247 (12): 3170-3175.

Minotti, G. and Aust, S.D. (1987). Investigation into the mechanism of citrate-Fe2+ dependent lipid peroxidation. Free radical Biology and Medicine. 3: 379-387.

Oboh, G., Puntel, R.L. and Rocha, J.B.T. (2007). Hot pepper (Capsicum annuum) prevents Fe ${ }^{2+}$ induced lipid peroxidation in brain in vitro. Food chemistry, 102: 178-185.

Ojo, O.A., Oloyede, O.I., Tugbobo, O.S., Olanrewaju, O., Ojo, A. (2014). Antioxidant and inhibitory effect of scent leaf (Ocimum gratissimum) on $\mathrm{Fe} 2+$ and sodium nitroprusside induced lipid peroxidation in rat brain in vitro. Advances in Biological Research, 8 (1): 8-17. [idosi.org] 
Rotruck, N.H., Hertwig, B., and Streb, J. (1973). Determination of glutathione peroxidase activity. Am. Journal of Clinical Pathol. 29: 511-515.

Spencer, J.P.E., Jenner, A. and Aruoma, O.I. (1994). Intense oxidative DNA damage promoted by L-DOPA and its metabolites. FEBS Letters. 353 (3): 246-250. 